\title{
A SOLAR COOLING PLANT: A BENCHMARK FOR HYBRID SYSTEMS CONTROL
}

\author{
Darine Zambrano* Carlos Bordons ** \\ Winston García-Gabín* Eduardo F. Camacho** \\ * Escuela de Ingeniería Eléctrica, Universidad de Los \\ Andes, Venezuela \\ ** Departamento de Ingenieria de Sistemas y Automatica, \\ Escuela Superior de Ingenieros, Universidad de Sevilla, \\ España
}

\begin{abstract}
This paper describes the hybrid model of a solar cooling plant. This model considers all possible operating modes of the process, which are modelled as a finite state machine whose transition conditions are given by the discrete variables. The discrete variables are the electrovalves and pumps. The model has been written as a mixed logical dynamical system and is simulated using Stateflow/Simulink Matlab. The model has been validated using real data from the plant. This plant is being used as a benchmark for hybrid control experiences by many European researchers in the framework of the HYCON Network of Excellence. Copyright (C) 2006 IFAC
\end{abstract}

Keywords: Hybrid system, dynamic models, solar energy.

\section{INTRODUCTION}

The use of solar energy in air conditioning systems is one of the most evident and not sufficiently exploited applications of this source of renewable energy. The use of solar radiation for cooling allows a time synchronization between solar offer and cooling demand since cold air is in general more necessary when the solar radiation is high, reducing this way the need of storage systems, which is one of the drawbacks of the use of solar energy for other application such as heating.

There exist different procedures for cold production which have been tested using solar radiation as primary source (see (Sayigh and (editors), 1992)). One of the most successful methods is by means of an absorption machine, which produces chilled water when hot water is injected into its generator. As the water is heated by the sun, this type of air conditioning systems reduces conventional energy consumption and therefore contributes to the maintenance of a non-polluted air. The plant includes buffer storage and an auxiliary energy system to be used in the case that the solar energy supply is not enough.

However, the operation of this type of system presents some particular issues that must be addressed by the control strategy. Firstly, the primary energy (sun) cannot be manipulated, as is the case of any conventional thermal process. Secondly, there exist big disturbances on the process, mainly due to the change in environmental conditions. There are also dead-times associated to fluid transportation, which are variable depending on the operating conditions. Finally, the cooling demand is variable, since it depends on the occupancy and use of the space (laboratories in this case).

In addition to this, its dynamics changes depending of the source of energy (solar, auxiliary heater, storage tank or a combination of them) that is used to feed the absorption machine. Several control strategies have been tested on different solar power plants (see, for instance, (Camacho et al., 1997; Lemos et al., 2002; Silva et al., 2002)), but none 
of them takes the hybrid nature of the process into account.

This process presents many continuous and discrete variables and presents multiple operating modes. The operating modes are defined by the components that provide thermal energy to the absorption machine. For these characteristics, this process has to be modelled as a hybrid system. The hybrid model represents the continuous and discrete components, and allows configuration of the operating modes. The models have been obtained using energy balances, physical laws, and models based in practical data, and are validated with real data.

This paper shows the development of a hybrid model of the whole plant, which is validated through experiments performed on the real plant. A simulation model is obtained as a useful tool for analysis and controller design.

This plant is used in the framework of the Network of Excellence HYCON, whose objective is to establish a durable community of leading researchers and practitioners working in hybrid systems control. This solar plant is a performance evaluation platform for testing control technologies of hybrid systems. Another benchmark problem is included in HYCON: an idle speed motor control system (Balluchi et al., 2006).

The paper is organized as follows: Section 2 presents a description of the solar cooling plant, the principal systems and the operating modes are described. The hybrid models of the components are derived in section 3. Section 4 is devoted to the implementation and experimental validation of the model and finally the conclusions of the work are presented in section 5 .

\section{PLANT DESCRIPTION}

The solar air conditioning plant is located at Seville (Spain) and is used to cool the Laboratories of the System Engineering and Automation Department of the University of Seville. It consists of a solar field that produces hot water which feeds an absorption machine which generates chilled water and injects it into the air conditioning system, achieving a cooling power of $35 \mathrm{~kW}$.

A general scheme of the plant is shown in Fig. 1, showing its main components: the solar system, composed of a set of flat solar collectors, the accumulation system, composed of two tanks storing hot water, and the cooling machine. There also exist an auxiliary gas-fired heater that can supply energy in those situations where solar radiation is not enough, and a load simulator (a heat pump) that allows to perform tests for different load profiles.

The control objective is to supply chilled water to the air distribution system at the demanded tempera-

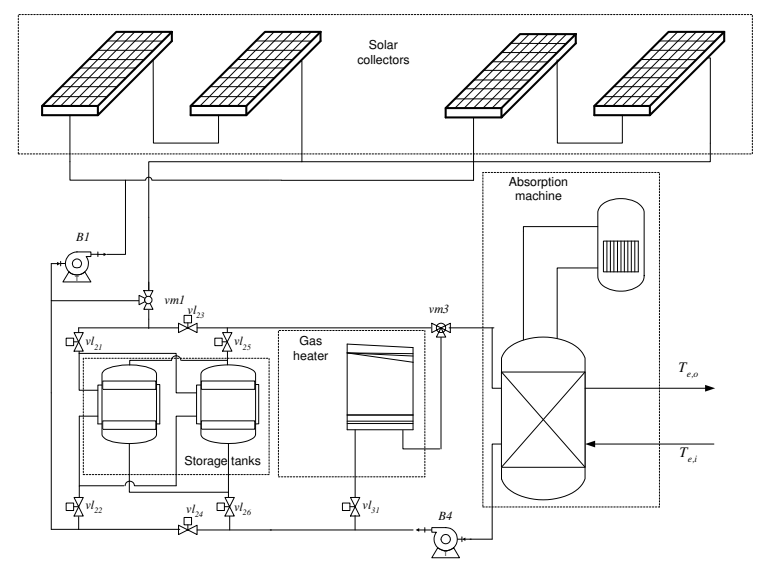

Fig. 1. Plant scheme

ture minimizing auxiliary energy (gas) consumption and fulfilling operational constraints in the absorption machine. Also, the storage energy in the tanks is considered at the end of the day, since it can be used in the following day when the solar radiation is low. The primary energy source (solar radiation) cannot be manipulated and has to be treated as a measurable disturbance. This implies that the control system must keep the cooling machine working at the desired operating point and this is achieved by keeping the machine inlet water temperature at the given set-point. The inlet water is the mix of the water coming from the solar system, the storage tanks and the water coming from the gas-fired heater in case additional energy is needed. Additionally, the temperature of the water in the solar system can be controlled adjusting the water flow inside the solar field.

The hybrid nature of the plant comes from the use of two different energy sources (solar and gas), which can be combined or used independently. Besides, thermal energy coming from a storage tank can be added to the system. The plant can be reconfigured on-line manipulating electrovalves and pumps (on/off) to allow selecting the components for energy supply.

\subsection{Systems description}

This section shows the main components of the plant.

Solar system: The primary source of energy is solar radiation, which is used by the solar collectors to increase the temperature of the circulating water. The solar field is composed of $151 \mathrm{~m}^{2}$ of flat collectors which work in the range of $60^{\circ} \mathrm{C}$ to $100^{\circ} \mathrm{C}$ and supply a nominal power of $50 \mathrm{~kW}$.

Accumulation system: The accumulation system is composed of two tanks of $2500 \mathrm{~L}$ each one, that work in parallel. This system acts as a buffer, storing hot water to be used in transient situations where 
solar radiation does not allow to obtain the desired temperature at the end of the hot water circuit.

Auxiliary energy system: As a complement to the solar energy supplied by the field, an auxiliary energy system consisting of a gas-fired heater of $60 \mathrm{~kW}$ can be used in case solar radiation is not enough. This heater transfers additional thermal energy to the water coming from the collectors. The existing heater has a built-in ON/OFF controller, which makes its outlet temperature rather oscillatory.

Cooling system: The cooling system is an absorption machine that works with water as cooling fluid and a water solution of lithium bromide $\left(\mathrm{H}_{2} \mathrm{O}-\mathrm{LiBr}\right)$. The correct operating of the machine requires that its inlet temperature is inside the range of $75^{\circ} \mathrm{C}-100^{\circ} \mathrm{C}$ for chilled water production. The machine has four different circuits: evaporator, generator, condenser and absorber, where the energy exchanges for chilled water production take place. The experimental results are similar to (Syed et al., 2005). The critical variables that have influence on operation are:

- Condenser temperature, which establishes condenser and generator pressures.

- Evaporator temperature, which establishes evaporator and absorber pressures.

- Generator temperature, that together with condenser pressure fixes the solution concentration that leaves the generator.

- Absorber temperature, that together with the evaporator pressure fixes the solution concentration that enters the generator.

Continuous manipulated variables: The continuous variables are the pump velocity $\left(v_{B 1}\right)$ and the mix valve position $\left(v p_{v m 3}\right)$.

Discrete manipulated variables: The logic manipulated variables are the electrovalves and pumps,

- $v l_{21} / v l_{22}$ allows connect the solar collectors with the tanks

- $v l_{23} / v l_{24}$ allows connect the solar collectors with the absorption machine/gas heater

- $v l_{25} / v l_{26}$ allows connect the tanks with the absorption machine/gas heater

- $v l_{31}$ allows circulate water through the gas heater

- B4 allows pump water from absorption machine (constant velocity)

- B1 allows pump water through solar collectors (variable velocity)

- vm1 allows flow the water to solar collectors or to the other components

\subsection{Operating modes of the process}

The plant evolves among several operating modes during its daily operation. A logic variable " $l_{i}$ " is associated to each operating mode. The operating modes are selected using pumps and ON/OFF valves and are the following:

(1) Recirculation $\Rightarrow l_{1}=1$ : All water flow through the solar collectors. In this mode, the temperature of the water is elevated.

(2) Loading the tanks with hot water $\Rightarrow l_{2}=1$ : The water in the solar collectors flows through the tanks. When a little solar radiation is appeared, then the stored hot water is used.

(3) Using the solar collectors $\Rightarrow l_{3}=1$ : The water is heated in the solar collectors. The water flows to absorption machine.

(4) Using the solar collectors and gas heater $\Rightarrow l_{4}=$ 1: The water is heated in the solar collectors and the gas heater. The gas heater is used when the absorption machine input temperature is inadequate. The gas heater on must be avoided.

(5) Using the gas heater $\Rightarrow l_{5}=1$ : The water is heated in the gas heater, and then it flows through the absorption machine.

(6) Using the tanks and gas heater $\Rightarrow l_{6}=1$ : The water of absorption machine is given by the tanks. The gas heater is used when the absorption machine input temperature is not enough. The gas heater on must be avoided too.

(7) Using tanks $\Rightarrow l_{7}=1$ : When little solar radiation is appeared, then the heat stored in the tanks is used to operate the absorption machine.

(8) Loading the tanks and using the gas heater $\Rightarrow$ $l_{8}=1$ : The tanks are loaded with heated water by the solar collectors. The water of absorption machine is given by the gas heater.

(9) Recirculation and using the gas heater $\Rightarrow l_{9}=$ 1: The water is recirculated through the solar collectors. The water to the absorption machine from the gas heater only.

(10) Using the solar collectors and loading tank $\Rightarrow$ $l_{10}=1$ : The water from the solar collectors is divided into the tanks and the absorption machine.

(11) Using the solar collectors and gas heater, and loading tanks $\Rightarrow l_{11}=1$ : The water from the solar collectors is divided into the tanks and the absorption machine. The inlet water to the absorption machine is from the solar collectors and gas heater.

\section{HYBRID MODEL}

A hybrid model has been developed using a Finite State Machine (FSM). The transition conditions are given by the discrete manipulated variables (1),

$$
\begin{aligned}
& c 1=\sim v l_{21} \wedge \sim v l_{23} \wedge \sim v l_{25} \wedge \sim v l_{31} \wedge \sim B 4 \wedge B 1 \wedge \sim v m 1 \\
& c 2=v l_{21} \wedge \sim v l_{23} \wedge \sim v l_{25} \wedge \sim v l_{31} \wedge \sim B 4 \wedge B 1 \wedge v m 1 \\
& c 3=\sim v l_{21} \wedge v l_{23} \wedge \sim v l_{25} \wedge \sim v l_{31} \wedge B 4 \wedge B 1 \wedge v m 1 \\
& c 4=\sim v l_{21} \wedge v l_{23} \wedge \sim v l_{25} \wedge v l_{31} \wedge B 4 \wedge B 1 \wedge v m 1 \\
& c 5=\sim v l_{21} \wedge \sim v l_{23} \wedge \sim v l_{25} \wedge v l_{31} \wedge B 4 \wedge \sim B 1
\end{aligned}
$$




$$
\begin{aligned}
c 6 & =\sim v l_{21} \wedge \sim v l_{23} \wedge v l_{25} \wedge v l_{31} \wedge B 4 \wedge \sim B 1 \\
c 7 & =\sim v l_{21} \wedge \sim v l_{23} \wedge v l_{25} \wedge \sim v l_{31} \wedge B 4 \wedge \sim B 1 \\
c 8 & =v l_{21} \wedge \sim v l_{23} \wedge \sim v l_{25} \wedge v l_{31} \wedge B 4 \wedge B 1 \wedge v m 1 \\
c 9 & =\sim v l_{21} \wedge \sim v l_{23} \wedge \sim v l_{25} \wedge v l_{31} \wedge B 4 \wedge B 1 \wedge \sim v m 1 \\
c 10 & =v l_{21} \wedge v l_{23} \wedge \sim v l_{25} \wedge \sim v l_{31} \wedge B 4 \wedge B 1 \wedge v m 1 \\
c 11 & =v l_{21} \wedge v l_{23} \wedge \sim v l_{25} \wedge v l_{31} \wedge B 4 \wedge B 1 \wedge v m 1
\end{aligned}
$$

In the figure 2 is shown the FSM of the solar plant implemented in Stateflow. The state output is the operating mode of the process.
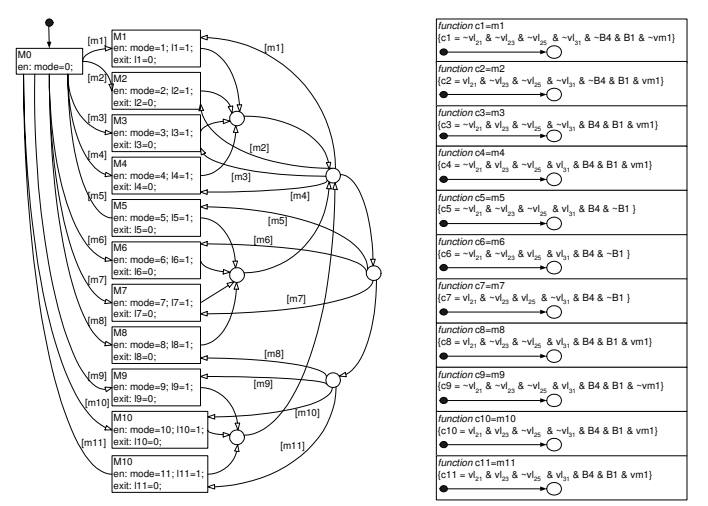

Fig. 2. Finite state machine of the solar plant

The states are the operating modes of the process (see 2.2). The state outputs are the logic variables $l_{1}, l_{2}, \ldots, l_{11}$. This logic variables are included in the model equations of each subsystem. The model equations have been written as a Mixed Logic Dinamycal (MLD) system (Bemporad and Morari, 1999).

The logic variables $l_{i}$ are included in the energy balance equations. The variables determine when a system is on. When a system is not working, the environmental losses are modelled. The input temperatures and the flows of each system are select by the logic variables.

\subsection{Solar collectors model}

A solar collector can be modeled as a heat exchanger that absorbs part of the solar radiation, warms up the circulating fluid and has some thermal losses. The equation that represents its behaviour can be obtained by means of energy balance and is given by:

\section{Solar collector output temperature}

$$
\begin{aligned}
& \left.\left[\begin{array}{ll}
C_{A} L_{1}+C_{E}(1 & L_{1}
\end{array}\right)\right] \frac{d T_{s c, m}}{d t}=\left[F\left(I_{G}+U\left(T_{a m b} \quad T_{s c, m}\right)\right)\right. \\
& +\frac{2 \dot{m}_{s c} C_{p}}{A_{C}}\left(\begin{array}{lll}
T_{s c, i} & T_{s c, m}
\end{array}\right] L_{1}+\left[\begin{array}{lll}
U_{E}\left(T_{a m b}\right. & \left.\left.T_{s c, m}\right)\right]\left(\begin{array}{ll}
1 & L_{1}
\end{array}\right) \\
T_{s c, o}=2 T_{s c, m} & T_{s c, i}
\end{array}\right.
\end{aligned}
$$

Solar collectors logic condition

$$
L_{1}=l_{1}+l_{2}+l_{3}+l_{4}+l_{8}+l_{9}+l_{10}+l_{11}
$$

Solar collector input temperature

$$
\begin{aligned}
& T_{s c, i}(t)=T_{s c, o}\left(\begin{array}{ll}
t & t_{m}
\end{array}\right)\left(l_{1}+l_{9}\right)+T_{t s c, o}\left(\begin{array}{l}
t \\
t_{m}
\end{array}\right)\left(l_{2}+l_{8}\right) \\
& +T_{g, o}\left(\begin{array}{ll}
t & t_{m}
\end{array}\right)\left(l_{3}+l_{4}\right)+\frac{\left(\begin{array}{ll}
\dot{m}_{s c} & \dot{m}_{g}
\end{array}\right) T_{t s c, o}+\dot{m}_{g} T_{g, o}}{\dot{m}_{s c}} l_{10}
\end{aligned}
$$

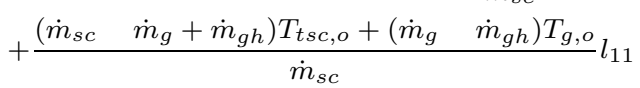

where $T_{s c, m}$ is the average temperature of the water inside the collector $\left({ }^{\circ} \mathrm{C}\right), T_{s c, i}$ is the inlet water temperature $\left({ }^{\circ} \mathrm{C}\right), T_{a m b}$ is the ambient temperature $\left({ }^{\circ} \mathrm{C}\right), C_{A}$ is the heat capacity per surface unit of the collector $\left(\frac{\mathrm{J}}{{ }^{\circ} \mathrm{Cm}^{2}}\right), C_{p}$ is the heat capacity of water $\left(\frac{J}{k_{g}{ }^{\circ} C}\right), U$ is the coefficient of losses to the atmosphere $\left(\frac{W}{{ }^{\circ} \mathrm{Cm}^{2}}\right), I_{G}$ is the irradiation on the collector surface $\left(\frac{W}{m^{2}}\right), A_{C}$ the collector area $\left(m^{2}\right)$, $T_{t s c, o}$ is the output temperature to solar collectors $\left({ }^{\circ} \mathrm{C}\right), T_{g, o}$ is generator outlet temperature $\left({ }^{\circ} \mathrm{C}\right), U_{E}$ is the coefficient of losses to the ambient and $C_{E}$ is the time constant when B1 pump is off, $F$ is the efficiency factor, $\dot{m}_{g h}$ is the water mass through the gas heater $\left(\frac{\mathrm{kg}}{\mathrm{s}}\right), t_{m}$ is the transport delay $(\mathrm{s}), \dot{m}_{g}$ is the water mass flow in the generator $\left(\frac{\mathrm{kg}}{\mathrm{s}}\right)$ and $\dot{m}_{s c}$ is the water mass flow through the collector $\left(\frac{\mathrm{kg}}{\mathrm{s}}\right)$. The output temperature of the collector, $T_{s c, o}$, is obtained assuming that the temperature distribution is linear.

\subsection{Accumulation model}

The equations that model the process are based on the energy balance. The tanks inner temperature has been considered. The inlets tanks are not open simultaneously. The transport delay of the output temperatures has been estimated in function of the flows intensity. The equations are:

Tanks temperature

$$
\begin{aligned}
& C_{p} V_{t} \rho \cdot \frac{d T_{t}}{d t}=\dot{m}_{t s c} C_{p}\left(T_{t s c, i} \quad T_{t}\right) \\
& +\dot{m}_{t a m} C_{p}\left(T_{t a m, i} \quad T_{t}\right)+U_{t} A_{t}\left(T_{a m b} \quad T_{t}\right)
\end{aligned}
$$

Tanks output temperature

$$
\begin{aligned}
T_{t s c, o}(t) & =T_{t}\left(t-t_{0 s c}\right)\left(l_{2}+l_{8}+l_{10}+l_{11}\right) \\
T_{\text {tam }, o}(t) & =T_{t}\left(t-t_{0 a m}\right)\left(l_{6}+l_{7}\right)
\end{aligned}
$$

Tanks input temperature

$$
\begin{aligned}
T_{t s c, i} & =T_{s c, o}\left(l_{2}+l_{8}+l_{10}+l_{11}\right) \\
T_{t a m, i} & =T_{g, o}\left(l_{6}+l_{7}\right)
\end{aligned}
$$

where $U_{t}$ is the tank loss coefficient per surface unit $\left(\frac{W}{{ }^{\circ} C \cdot m^{2}}\right), A_{t}$ are the surfaces of the control volume in contact with the environment $\left(\mathrm{m}^{2}\right), V_{t}$ are the slices volumes $\left(\mathrm{m}^{3}\right), \rho$ is water density $\left(\frac{\mathrm{kg}}{\mathrm{m}^{3}}\right), T_{t}$ is the tanks inner temperature $\left({ }^{\circ} C\right), \dot{m}_{t s c}$ is the water mass flow from solar fields $\left(\frac{\mathrm{kg}}{\mathrm{s}}\right), \dot{m}_{\text {tam }}$ is the water mass flow from absorption machine $\left(\frac{\mathrm{kg}}{\mathrm{s}}\right), T_{t s c, i}$ is the input temperature from solar collectors $\left({ }^{\circ} C\right), T_{\text {tam,i }}$ is the input temperature from absorption machine $\left({ }^{\circ} \mathrm{C}\right), T_{\text {tam,o }}$ is the output temperature to absorption machine $\left({ }^{\circ} C\right), t_{0 s c}$ is the transport delay to output solar collectors $(s)$ and $t_{0 a m}$ is the transport delay to absorption machine $(s)$. 


\subsection{Gas heater model}

A complete model can see in (Claquin et al., 1994). Heater equations model consider two temperatures evolution: gas temperature $\left(T_{c h}\right)$ and outlet water temperature $\left(T_{g w, o}\right)$ :

Water output temperature

$$
\begin{aligned}
& {\left[C_{a} L_{2}+C_{E}\left(\begin{array}{ll}
1 & L_{2}
\end{array}\right)\right] \frac{d T_{g w, o}}{d t}=\left[\begin{array}{ll}
U_{a w}\left(T_{a m b}\right. & T_{g w, o}
\end{array}\right)} \\
& \left.+U_{g w}\left(T_{c h} \quad T_{g w, o}\right)+k C_{p} \dot{m}_{g h}\left(T_{g w, i} \quad T_{g w, o}\right)\right] L_{2} l_{12} \\
& +U_{E}\left(T_{a m b} \quad T_{g w, o}\right)\left(1 \quad L_{2}\right)
\end{aligned}
$$

\section{Gas heater logic condition}

$$
L_{2}=l_{4}+l_{5}+l_{6}+l_{8}+l_{9}+l_{11}
$$

Gas output temperature

$$
\begin{gathered}
{\left[C_{g} L_{2}+C_{E}\left(1 \quad L_{2}\right)\right] \frac{d T_{c h}}{d t}=\left[\begin{array}{ll}
U_{a g}\left(T_{a m b}\right. & T_{c h}
\end{array}\right)} \\
\left.+U_{w g}\left(\begin{array}{lll}
T_{w g, o} & T_{c h}
\end{array}\right)+P\right] L_{2}+U_{E}\left(\begin{array}{ll}
T_{a m b} & T_{c h}
\end{array}\right)\left(\begin{array}{ll}
1 & L_{2}
\end{array}\right) \\
P=\dot{Q}_{o n} l_{13}+\dot{Q}_{o f f}\left(1 \quad l_{13}\right) \\
l_{12}=\left\{\begin{array}{lll}
1 & m_{g h} \geq 1500 & l / h \\
0 & m_{g h}<1500 & l / h
\end{array} ; l_{13}= \begin{cases}1 & T_{g w, o}<86^{\circ} \mathrm{C} \\
0 & T_{g w, o}>94^{\circ} \mathrm{C}\end{cases} \right.
\end{gathered}
$$

Gas input temperature

$$
T_{g w, i}(t)=T_{g, o}\left(t-t_{m}\right) L_{2}
$$

where $T_{g w, i}$ is the heater inlet water temperature, $C_{a}$ is water heat capacity $\left(\frac{W}{{ }^{\circ} C}\right), C_{g}$ is gas heat capacity $\left(\frac{W}{{ }^{\circ} C}\right), U_{a w}, U_{g w}, U_{w g}, U_{a g}$ are heat transfer coefficients $\left(\frac{W}{{ }^{\circ} C}\right), k$ is dimensionless constant, $U_{E}$ is the coefficient of losses to the ambient and $C_{E}$ is the time constant when the gas heater is off, and $\dot{Q}$ is the burner power $(W)$.

\subsection{Absorption machine model}

The equations that describes the behavior of water temperature are given by:

\section{Generator output temperature}

$$
\begin{aligned}
& {\left[\left(C_{g m} l_{14}+C_{g o}\left(1 \quad l_{14}\right)\right) L_{3}+C_{E}\left(\begin{array}{ll}
1 & L_{3}
\end{array}\right)\right] \frac{d T_{g, o}}{d t}=} \\
& {\left[\dot{m}_{g}\left(T_{g, i} \quad T_{g, o}\right)+Q_{G} l_{14}\right] L_{3}+U_{a g m}\left(T_{a m b} \quad T_{g, o}\right)(1}
\end{aligned}
$$

Evaporator output temperature

$$
\begin{aligned}
& \left.\left[\begin{array}{ll}
\left(C_{e m} l_{14}+C_{e o}(1\right. & \left.l_{14}\right)
\end{array}\right) L_{3}+C_{E}\left(\begin{array}{ll}
1 & L_{3}
\end{array}\right)\right] \frac{d T_{e, o}}{d t}= \\
& {\left[\begin{array}{ll}
\dot{m}_{e}\left(T_{e, i}\right. & \left.T_{e, o}\right)+Q_{E} l_{14}
\end{array}\right] L_{3}+\operatorname{Uae}\left(T_{a m b} \quad T_{e, o}\right)(1} \\
& Q_{E}=C_{p} \dot{m}_{g}\left(T_{g, i} \quad T_{g, o}\right) C O P_{n}
\end{aligned}
$$

Absorption machine logic condition

$$
\begin{gathered}
L_{3}=l_{3}+l_{4}+l_{5}+l_{6}+l_{7}+l_{8}+l_{9}+l_{10}+l_{11} \\
l_{14}=\left\{\begin{array}{cc}
1 & 75^{\circ} \mathrm{C} \leq T_{g, i} \leq 100^{\circ} \mathrm{C} \\
0 & T_{g, i}<75^{\circ} \mathrm{C}, T_{g, i}>100^{\circ} \mathrm{C}
\end{array}\right.
\end{gathered}
$$

Generator input temperature

$$
\begin{aligned}
& T_{g, i}=T_{s c, o}\left(l_{3}+l_{10}\right)+T_{g w, o}\left(l_{5}+l_{8}+l_{9}\right) \\
& +\frac{\dot{m}_{s c} T_{s c, o}+\dot{m}_{g h} T_{g w, o}}{\dot{m}_{s c}+\dot{m}_{g h}} l_{4}+T_{t a m, o} l_{7} \\
& +\frac{\left(\dot{m}_{g} \quad \dot{m}_{g h}\right)\left(T_{t a m, o} l_{6}+T_{s c, o} l_{11}\right)+\dot{m}_{g h} T_{g w, o}\left(l_{6}+l_{11}\right)}{\dot{m}_{g}}
\end{aligned}
$$

where $\dot{m}_{e}$ is the water mass in the evaporator $\left(\frac{\mathrm{kg}}{\mathrm{s}}\right), T_{g, i}$ is inlet generator temperature $\left({ }^{\circ} \mathrm{C}\right), T_{e, o}$ is outlet evaporator temperature $\left({ }^{\circ} C\right), T_{e, i}$ is inlet evaporator temperature $\left({ }^{\circ} C\right), C_{g m}$ and $C_{e m}$ are the heat capacities in the generator and evaporator when the absorption machine is on $\left(\frac{W}{{ }^{\circ} C}\right), C_{g o}$ and $C_{e o}$ are the heat capacities in the generator and evaporator when the absorption machine is off $\left(\frac{W}{{ }^{\circ} C}\right), U_{a g m}$ and $U_{a e}$ are the thermal losses coefficients, $Q_{G}$ and $Q_{E}$ is the exchanged power in the generator and evaporator respectively, $C O P_{n}$ is the coefficient of performance.

\subsection{Flows models}

Finally, the solar collectors $\dot{m}_{s c}$, gas heater $\dot{m}_{g h}$ and absorption machine $\dot{m}_{g}$ flows have been identified. The flows depends of the pump velocity $v_{B 1}$ and the valve position $v p_{v m 3}$. The identification is based in the real data collected for each operating mode.

$$
\begin{aligned}
\dot{m}_{s c}= & f_{s 1}\left(v_{B 1}\right)\left(l_{1}+l_{9}\right)+f_{s 2}\left(v_{B 1}\right)\left(l_{2}+l_{8}\right)+ \\
& f_{s 3}\left(v_{B 1}, v p_{v m 3}\right) l_{3}+f_{s 4}\left(v_{B 1}, v p_{v m 3}\right) l_{4}+ \\
& f_{s 10}\left(v_{B 1}, v p_{v m 3}\right) l_{10}+f_{s 11}\left(v_{B 1}, v p_{v m 3}\right) l_{11} \\
\dot{m}_{g h}= & f_{g 4}\left(v_{B 1}, v p_{v m 3}\right) l_{4}+f_{g 5}\left(v p_{v m 3}\right)\left(l_{5}+l_{8}+l_{9}\right)+ \\
& f_{g 6}\left(v p_{v m 3}\right) l_{6}+f_{g 10}\left(v_{B 1}, v p_{v m 3}\right) l_{10}+ \\
& f_{g 11}\left(v_{B 1}, v p_{v m 3}\right) l_{11} \\
\dot{m}_{g}= & f_{m g 3}\left(v_{B 1}, v p_{v m 3}\right) l_{3}+f_{m g 4}\left(v_{B 1}, v p_{v m 3}\right) l_{4}+ \\
& f_{m g 5}\left(v p_{v m 3}\right)\left(l_{5}+l_{8}+l_{9}\right)+f_{m g 6}\left(v p_{v m 3}\right) l_{6}+ \\
& f_{m g 7}\left(v p_{v m 3}\right) l_{7}+f_{m g 10}\left(v_{B 1}, v p_{v m 3}\right) l_{10}+ \\
& f_{m g 11}\left(v_{B 1}, v p_{v m 3}\right) l_{11} \\
\dot{m}_{t s c}= & \dot{m}_{s c}\left(l_{2}+l_{8}\right)+\left(\dot{m}_{s c} \quad \dot{m}_{g}\right) l_{10}+ \\
& \left(\dot{m}_{s c} \quad \dot{m}_{g}+\dot{m}_{g h}\right) l_{11} \\
\dot{m}_{t a m}= & \left(\dot{m}_{g} \quad \dot{m}_{g h}\right) l_{6}+\dot{m}_{g} l_{7}
\end{aligned}
$$

\section{MODEL VALIDATION}

In order to validate the hybrid model, different experiments have been realized in the real plant. Firstly, the validation of the subsystems was done individually. Therefore, the complete model was validated.

The figure 3 shows the validation in the recirculation mode $\left(l_{1}=1\right)$, the real data have been collected on $12 / 27 / 05$. The real solar collectors temperature (solid line) and the simulated solar collectors temperature (dash line) are shown, the ambient temperature (dash-dot line) too. In this mode, the collectors temperature behavior depend on the solar radiation. The solar radiation shows a cloudy day, the simulation is between 10:45 and 14:00 hours. The model is able to follow the solar radiation variation. The solar radiation is a important variable, it is the principal energy source and a disturbance. The ambient temperature has little variations. The flow in the solar collectors are showed, the solid line is 
the simulated flow and the dash line is the real flow. The real flow has fluctuations in spite of the pump velocity is fixed. In this case, the solar energy is not enough for the absorption machine operation.
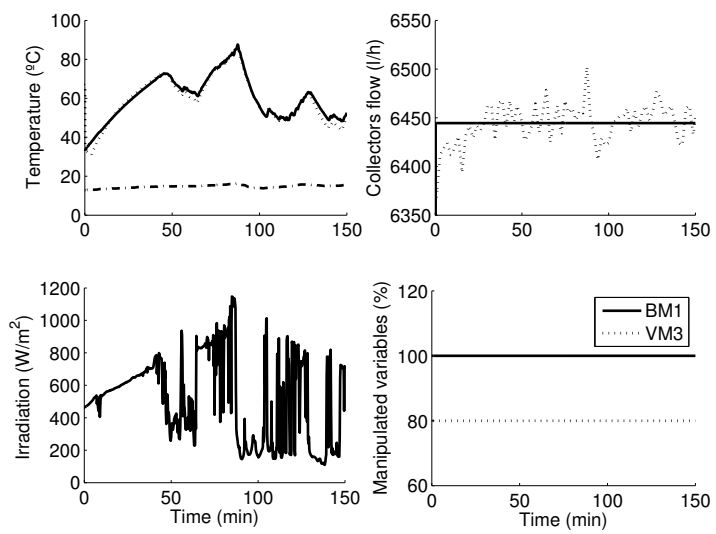

Fig. 3. Recirculation mode

Figure 4 shows the validation using the gas heater $\left(l_{5}=1\right)$. The experiment was done the $12 / 01 / 05$, at 15:45 hours. The real (dash line) and simulated (solid line) generator input temperature are shown. The temperatures have an adequate value for the absorption machine operation $\left(T_{g, i}>75^{\circ} \mathrm{C}\right)$ in at $11^{\prime} 15^{\prime}$ ' and at $12^{\prime} 00^{\prime \prime}$ minutes respectively. When the generator output temperature is higher than $75^{\circ} \mathrm{C}$, the refrigeration process began. The evaporator input temperature (dash-dot line) is given by a load simulator, the initial value is $30^{\circ} \mathrm{C}$. The real (dash line) and simulated (solid line) evaporator output temperature have a similar behavior. In each time instant, the chilled water decreases $5^{\circ} \mathrm{C}$ approx . The evaporator flow is shown, the mixed valve position $v p_{v m 3}$ is constant after of 3 minutes, the real flow (dash line) has little variations.
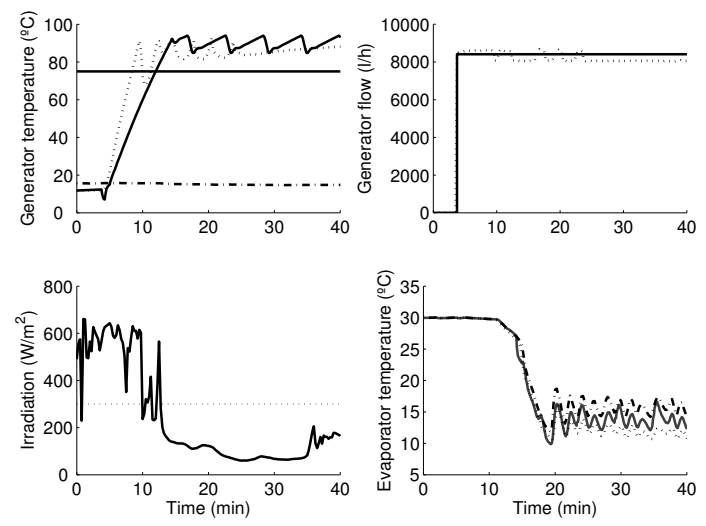

Fig. 4. Using the gas heater

The simulation compares the real data with the simulated data of the principal subsystems of the solar plant.

\section{CONCLUSIONS}

An hybrid model of the solar plant has been realized. The principal subsystems of the plant are modelled using energy balance equations, and the flow models are realized through identification using real data. The complete hybrid model is written using the logic variables corresponding to each operating mode. The hybrid model simulates the real behaviour of the solar plant according to the discrete and continuous manipulated variables. The hybrid model has been validated for different operating modes with satisfactory results. Future research will be devoted to develop the hybrid controller for this process.

\section{ACKNOWLEDGMENTS}

Supported by the Programme $\mathrm{Al} \beta$ an, the European Union Programme of High Level Scholarships for Latin America scholarship $\mathrm{N}^{\circ}$ E05D053808VE and European Union project HYCON(FP6-511368).

\section{REFERENCES}

Balluchi, Andrea, Luca Benvenuti, Maria D. Di Benedetto, Claudio Lemma, Pierpaolo Murrieri, Tiziano Villa and Alberto L. SangiovanniVincentelli (2006). Idle speed control: a benchmark for hybrid system design. Submitted to 2nd IFAC Conference on Analysis and Design of $\mathrm{Hy}$ brid Systems.

Bemporad, Alberto and Manfred Morari (1999). Control of systems integrating logic, dynamics and constraints. Automatica 35, 407-427.

Camacho, E.F., M. Berenguel and F.R. Rubio (1997). Advanced Control of Solar Plants. Springer. London.

Claquin, Sandrine, Alain Carriere and François Rocaires (1994). Modelling and application of adaptive control to a gas heater. Proceedings of the Third IEEE Conference on Control Applications.

Lemos, J. M., E. Mosca, R. N. Silva and P. O. Shirley (2002). Industrial applications of predictive adaptive control based on multiple identifiers. 15th IFAC World Congress.

Sayigh, A. M. and J.C. McVeigh (editors) (1992). Solar Air Conditioning and Refrigeration. Pergamon Press.

Silva, R. N., L. M. Rato and J.M. Lemos (2002). Observer based non uniform sampling predictive controller for a solar plant. 15th IFAC World Congress.

Syed, A., M. Izquierdo, P. Rodriguez, G. Maidment, J. Missenden, A. Lecuona and R. Tozer (2005). A novel esperimental investigation of a solar cooling system in madrid. International Journal of Refrigeration. 